\title{
INTERNAL HEMIPELVECTOMY: REPORT ONEIGHT CASES
}

Alexandre Ferreira Oliveira', Leonardo José Vieira², Antônio Carlos Rodrigues do Nascimento ${ }^{3}$, João Baptista de Paula Fraga ${ }^{4}$, Rómmel Ribeiro Lourenço Costa ${ }^{5}$, Luiz Gustavo Rodrigues do Nascimento ${ }^{5}$

\section{ABSTRACT}

Internal hemipelvectomy is a surgical procedure adequate for treatment of certain tumors of the pelvic girdle. Being a lower limb-preserving approach, it is a therapeutic alternative to the classical interilioabdominal amputation and hip joint disarticulation. According to Enneking's classification, there are four types of internal hemipelvectomies, although the association of different types of resection in the same procedure is feasible if necesary. This surgical approach should be correctly indicated to positively affect the patient's morbidity, mortality and quality of life. We report eight cases of internal hemipelvectomy in patients diagnosed with tumors of the pelvic girdle. We also discuss the neoadjuvant and adjuvant treatments used, along with their follow-up.

Keywords - Hemipelvectomy; Pelvic Neoplasms/surgery; Drug Therapy; Radiotherapy

\section{INTRODUCTION}

Internal hemipelvectomy consists of a resection of bone segments and compromised tissues of the pelvic girdle, preserving the femoral vascular-nervous bundle and the sciatic nerve, and in this way making it possible to preserve the lower limb of the patient ${ }^{(1)}$.

This procedure is split into four types according to the Enneking classification. Type I consists of resection of the ileum, which may or may not include the gluteal muscles, type II is periacetabular resection, which may or may not include the hip joint, type III consists of resection of the ischium and pubis, and type IV consists of resection of the whole hemipelvis $^{(1-6)}$ (Figure 1).

We report eight cases of patients diagnosed with tumors of the pelvic girdle, three of which were chondrosarcomas, two Ewing's sarcomas, one pleomorphic sarcoma, one chondromyxoid fibroma and one radioinduced osteosarcoma. All patients underwent internal hemipelvectomy by the same team of oncological surgeons of Juiz de Fora, MG. The study in question was approved by the Research Ethics Committee of the Oncology Institute.

\section{CASE REPORT}

Between November 2003 and December 2009, eight patients diagnosed with pelvic tumors underwent internal hemipelvectomy. Six patients were female and two were male. The patients had a mean age of 31.12 years (11-48). The histological types found were chondrosarcoma, Ewing's sarcoma, pleomorphic sarcoma, chondromyxoid fibroma, and radioinduced osteosarcoma. All patients in question had an indication for internal hemipelvectomy. An inverted Y incision was performed in only one patient. In the others, we made an inverted $\mathrm{V}$ incision (Figure 2). The procedure involves extensive tissue detachment to release the femoral vascular-nervous bundle and

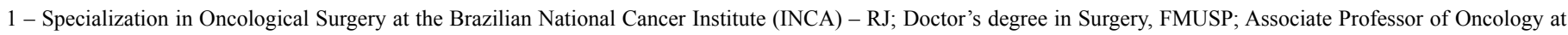
the Universidade Federal de Juiz de Fora - Juiz de Fora, MG, Brazil.

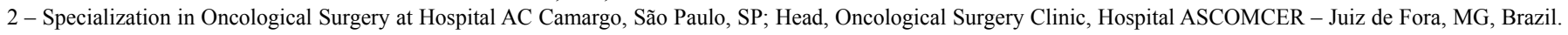

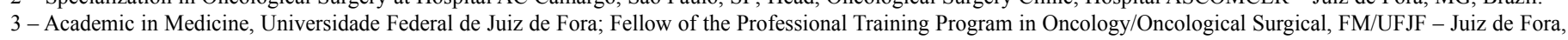
MG, Brazil.

4 - Specialization in Coloproctology, Hospital Heliópolis, SP; Full Member of the Brazilian Society of Coloproctology - São Paulo, SP, Brazil.

5 - Academic in Medicine, Universidade Federal de Juiz de Fora - Juiz de Fora, MG, Brazil.

Study conducted at the Oncology Institute - Juiz de Fora, MG.

Correspondence: Rua Padre Café, 472/801, Bairro São Mateus - 36016-450 - Juiz de Fora, MG, Brazil. Email: @ alexfer.oliveira ig.com.br

Received for publication: 9/16/2012, accepted for publication: 12/13/2012.
}

The authors declare that there was no conflict of interest in conducting this work 


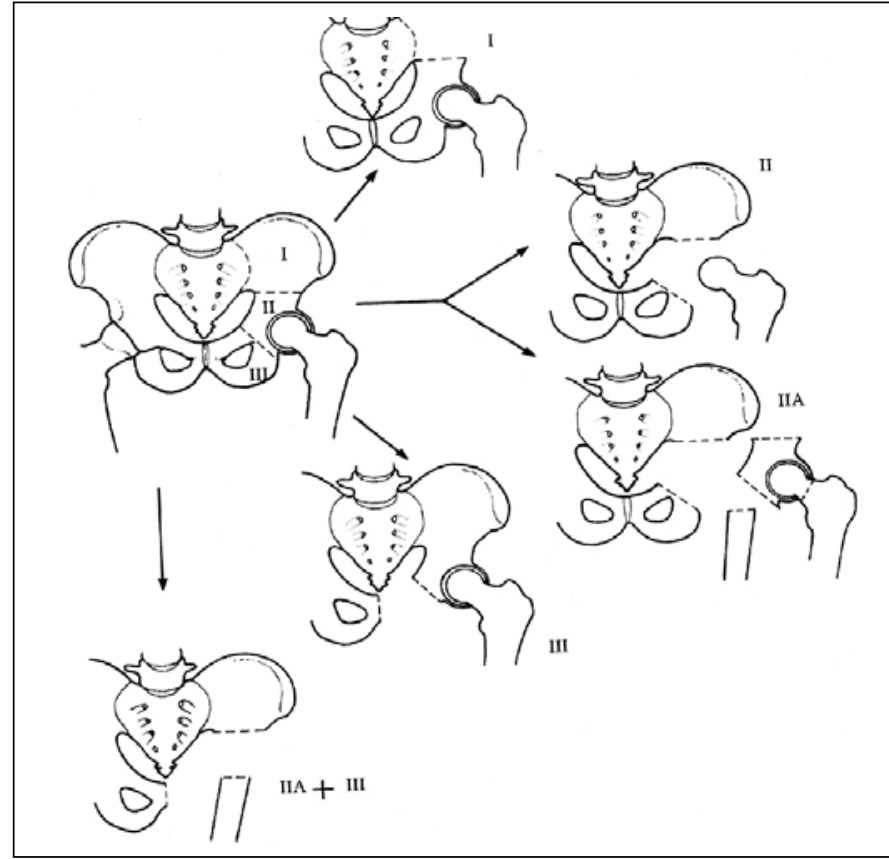

Figure 1 - Types of internal hemipelvectomy.

Source: Atlas of surgery for bone and soft tissue sarcomas, 2003.

the sciatic nerve (Figure 3). All patients underwent ligature of the epigastric and circumflex veins and arteries in order to decrease the risk of injury. Bone was resected with a gigli saw or power saw. Vigorous hemostasis was then performed prior to the placement of a suction drain. None of the patients underwent prosthesis placement (Figure 4). The histology and types of surgery performed are shown in Table 1.

Free surgical margins ( $\mathrm{R} 0$ resection) were obtained in six patients $(75 \%)$ and positive margins ( $\mathrm{R} 1 \mathrm{resec}-$ tion) were observed in two $(25 \%)$. Five patients are disease-free and two patients died, one due to pulmonary metastasis and the other due to locoregional recurrence. One patient is receiving treatment for pulmonary metastasis. The follow-up of patients, as well as the types of adjuvant and neoadjuvant treatment they have undergone, are shown in Table 2.

\section{DISCUSSION}

The main histological types of pelvic tumors are chondrosarcoma in adults, osteosarcoma in adolescents and youth, and Ewing's sarcoma in children ${ }^{(1,5)}$, which is in agreement with our sample (Figure 5).

Obtaining surgical margins similar to that of a classic amputation, the lack of tumor involvement in the femoral vascular-nervous bundle and the sciatic nerve, preserving partial function of the lower limb, and the patient having favorable life expectancy

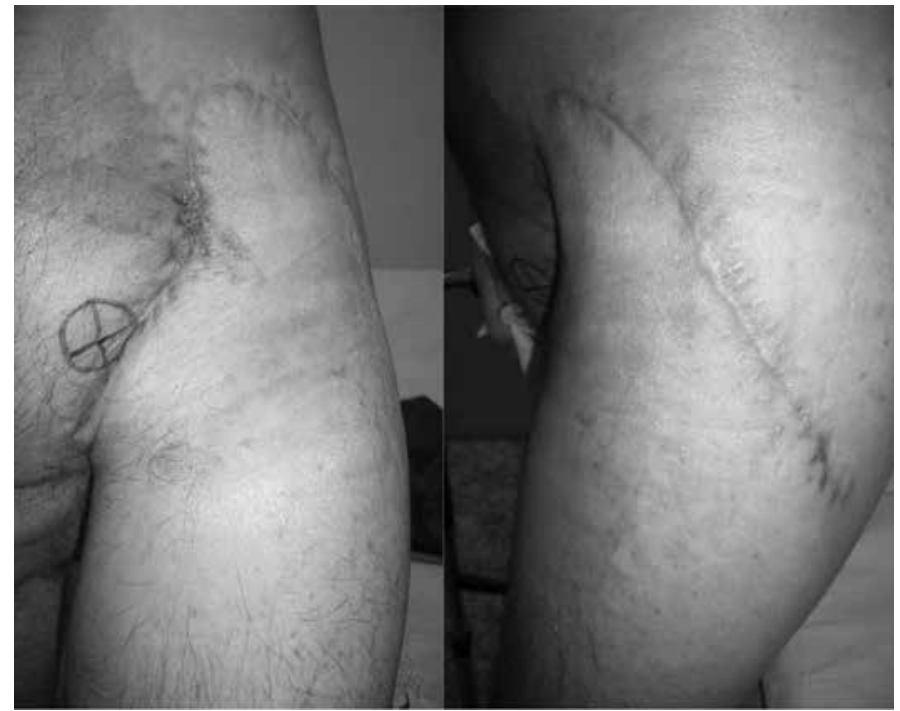

Figure 2 - Operative wound of a patient who underwent left internal hemipelvectomy 100 days ago. Incision was made in inverted V.

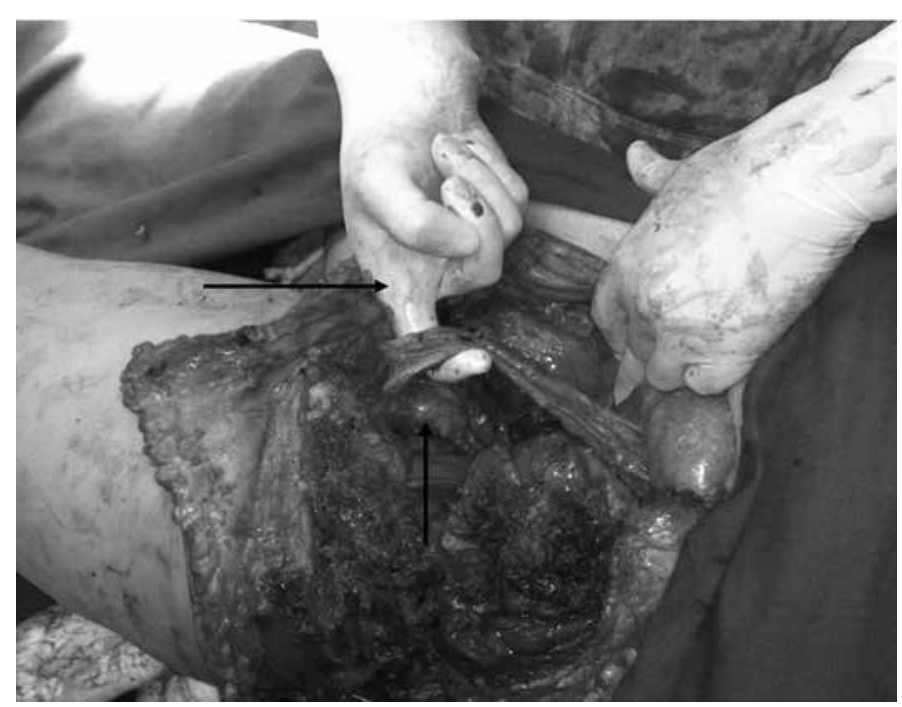

Figure 3 - Photo of the internal hemipelvectomy surgery showing the preservation of the femoral vascular-nervous bundle anteriorly and of the sciatic nerve posteriorly.

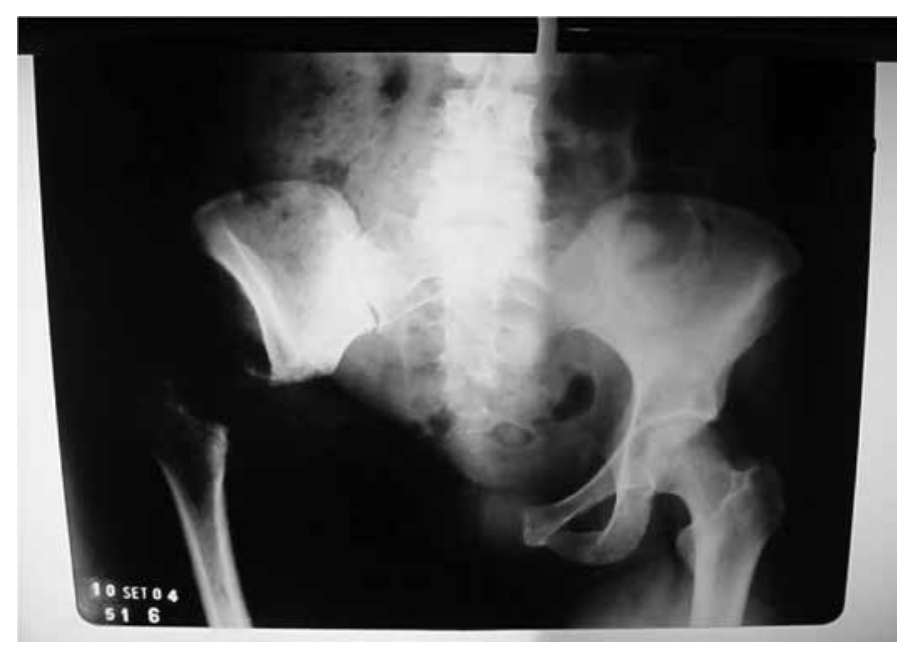

Figure 4 - X-ray of a patient previously submitted to right internal hemipelvectomy. Enneking II + III resection. 
Table 1 - Histological types of pelvic girdle tumors diagnosed and types of internal hemipelvectomy performed.

\begin{tabular}{c|c|c|c|c}
\hline Patients & Age/Sex & Histological type & Date of surgery & Type of surgery \\
\hline $\mathbf{1}$ & $11 /$ male & Ewing & (July/2004) & Left I.H. I \\
\hline $\mathbf{2}$ & $13 / \mathrm{female}$ & Ewing & (September/2006) & Left I.H. II+III \\
\hline $\mathbf{3}$ & $36 / \mathrm{female}$ & Pleomorphic sarcoma & Left I.H. III \\
\hline $\mathbf{4}$ & $37 /$ March/2009) & Left I.H. II+III \\
\hline $\mathbf{5}$ & $43 / \mathrm{female}$ & Chondrosarcoma grade III & (November/2003) & Left I.H. II+III \\
\hline $\mathbf{6}$ & $48 /$ Chemale & Chondrosarcoma grade III & Right I.H. II+III \\
\hline $\mathbf{7}$ & $48 / f e m a l e$ & Chondromyxoid fibroma & (November/2009) & Left I.H. I \\
\hline $\mathbf{8}$ & $13 /$ female & Radioinduced osteosarcoma & Right I.H. III \\
\hline
\end{tabular}

I.H.: Internal hemipelvectomy.

Table 2 - Types of adjuvant and neoadjuvant treatment and follow-up of patients.

\begin{tabular}{c|c|c|c|c|c}
\hline Patients & Neoadjuvant treatment & Adjuvant treatment & Disease-free & Locoregional recurrence & Distant metastases \\
\hline $\mathbf{1}$ & Chemo w/ IFO + VP/VADIC & Chemo w/ IFO + VP/VADIC & Death July/2008 & No & Lung and bones \\
\hline $\mathbf{2}$ & Chemo w/ IFO + VP/VADIC & $\begin{array}{c}\text { Chemo w/ IFO + VP/VADIC } \\
\text { No }\end{array}$ & $\begin{array}{c}\text { Chemo w/ IFO + ADM } \\
\text { and Radio }\end{array}$ & Nes & No \\
\hline $\mathbf{3}$ & No & $\begin{array}{c}\text { Chemo w/ IFO + ADM } \\
\text { and Radio }\end{array}$ & Yes & No & No \\
\hline $\mathbf{4}$ & No & No & Yes & No & No \\
\hline $\mathbf{5}$ & No & $\begin{array}{c}\text { Chemo w/ IFO + ADM } \\
\text { and Radio }\end{array}$ & Death June/2009 & No \\
\hline $\mathbf{6}$ & No & No & Yes & No & No \\
\hline $\mathbf{8}$ & No & Chemo w/ TOPO + CTX & Yes & No \\
\hline
\end{tabular}

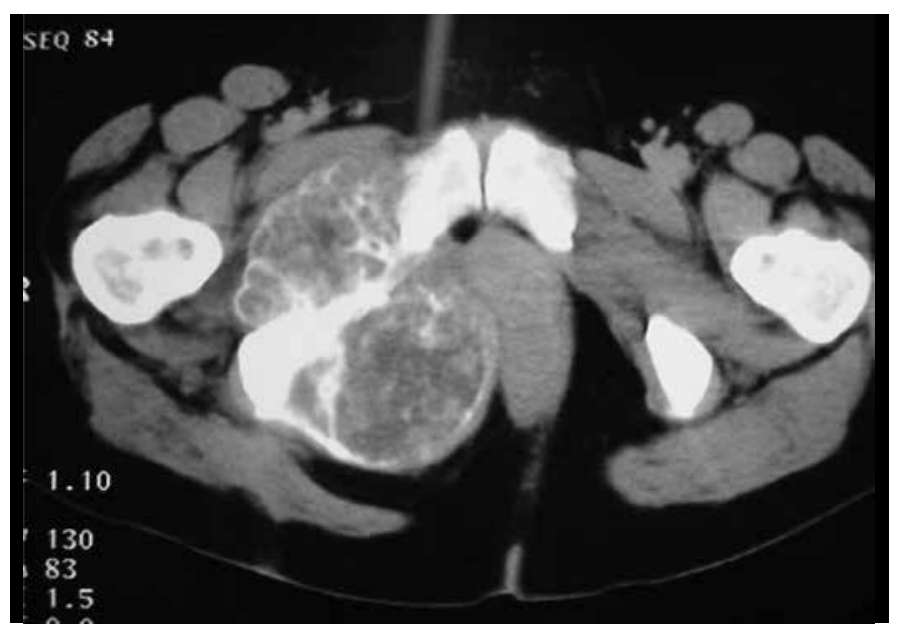

Figure 5 - Computed tomography of the pelvis showing a pelvic tumor on the right. The histological diagnosis was compatible with the grade of the chondrosarcoma.

and medical conditions, are essential factors for performing internal hemipelvectomy. This procedure is contraindicated in cases of local recurrence after conservative surgery of the limbs, in tumors that extend posteriorly through the sacroiliac joint, in tumors with great infiltrative potential, and those that extend to the thigh ${ }^{(2)}$.
From one to three months after surgery, an area of fibrosis will form at the site of surgical resection, providing stability and support to the pelvic girdle, which will ensure that the patient has the ability to walk again using the operated limb, first with the help of a walker, which in time will become unnecessary. The preservation of the sciatic and femoral nerve, and sacral filaments guarantee the maintenance, at least in part, of certain movements of the lower limb related to the surgery, such as extension and flexion of the thigh and leg, dorsiflexion, and plantar flexion.

The main prognostic factor for patients with tumors of the pelvic girdle who have undergone the surgery in question is the type of surgical margins obtained. R0 resections interfere directly in patient morbidity and mortality, increasing their survival or even providing its cure ${ }^{(1,3,4)}$. Other prognostic factors are the degree of tumor differentiation, histology of the tumor, presence or absence of distant metastasis, and if surgery was performed within appropriate oncologic principles. A $27 \%$ incidence of disease recurrence after surgical treatment has been reported in the 
literature ${ }^{(1)}$. Only one of our patients had locoregional recurrence $(12.5 \%)$. Intra- and postoperative bleeding, flap ischemia, deep vein thrombosis, infections, sciatic neuritis, and others are significant complications in internal hemipelvectomy. The literature shows a $50 \%$ incidence in the rates of complications caused by surgery ${ }^{(1)}$, which was not found in our patients.
Internal hemipelvectomy is an adequate therapeutic alternative in certain cases of pelvic tumors and should be considered whenever possible, since, according to Lopes et $\mathrm{al}^{(1)}$, this procedure has a low recurrence rate comparable to other radical resections. In addition, it preserves the lower limb, positively influencing their quality of life.

\section{REFERENCES}

1. Lopes A, Penna B, Rossi BM, Wu TC, Tanaka MK. Hemipelvectomia total interna no tratamento dos tumores malignos da regiäo pélvica. Rev Bras Ortop. 1994;29(11/12):787-90.

2. Sugarbaker $\mathrm{PH}$. Atlas de cirurgia para sarcoma ósseos e de partes moles. São Paulo: Lemar; 2003

3. Lopes A, Morini S, Vieira LJ, de Oliveira AT. Chondrosarcoma secondary to hereditary multiple exostosis treated by extended internal hemipelvectomy. Sao Paulo Med J. 1997;115(3):1440-3.
4. Mankin HJ, Hornicek FJ. Internal hemipelvectomy for the management of pelvic sarcomas. Surg Oncol Clin N Am. 2005;14(2):381-96

5. Wirbel RJ, Schulte M, Maier B, Koschnik M, Mutschler WE. Chondrosarcoma of the pelvis: oncologic and functional outcome. Sarcoma. 2000;4(4):161-8.

6. Ham SJ, Schraffordt Koops H, Veth RP, van Horn JR, Eisma WH, Hoekstra HJ. External and internal hemipelvectomy for sarcomas of the pelvic girdle: consequences of limb-salvage treatment. Eur J Surg Oncol. $1997 ; 23(6): 540-6$ 